\title{
HISTÓRIA ORAL: RE-CONSTRUINDO A REALIDADE E AS RELAÇÕES SOCIAIS
}

\author{
Ana Lídia Cardoso do NASCIMENTO ${ }^{1}$ \\ Secretaria de Estado de Educação/PARÁ \\ analidia@ufpa.br
}

\begin{abstract}
Lembrar não é reviver, mas é re-fazer. É reflexão, compreensão do agora a partir do outrora; é sentimento, reaparição do feito e do ido, não sua mera repetição.

Marilena de Souza Chauí
\end{abstract}

Resumo: O trabalho a ser apresentado é resultado da dissertação apresentada ao Curso de Mestrado Internacional em Planejamento do Desenvolvimento, no Núcleo de Altos Estudos Amazônicos (NAEA), da Universidade Federal do Pará (UFPA), com o título "Escolas-família agrícola e agroextrativista no estado do Amapá: práticas e significados", sob a orientação da prof Dr $^{a}$ Lígia T. L. Simonian, defendida em março de 2005. O trabalho buscou a realização de estudo acerca das experiências das Escolas-Família do estado do Amapá, sob a perspectiva de percebêlas como alternativa de educação no meio rural com potencialidade de contribuir para o desenvolvimento rural do estado. As discussões para a construção da proposta dessas escolas originam-se nas lutas travadas pelos agricultores que, partindo da análise de sua realidade verificaram que as escolas rurais convencionais não atendiam aos seus interesses e que, a proposta pedagógica da EFA poderia se constituir em uma solução para a educação no ambiente rural. $O$ artigo tem a intenção de apresentar algumas questöes verificadas no decorrer do desenvolvimento da pesquisa no que se refere à aquisição de conhecimentos por meio da oralidade, garantindo o resgate histórico, cultural, social e econômico de um dado momento histórico.

Palavras-chave: História. Memória. Educação rural.

Abstract: The work to be presented is the result of the dissertation submitted in the curse of International Master in Planning of Development, in the Center for

\footnotetext{
1 Mestre em Planejamento do Desenvolvimento pelo Núcleo de Altos Estudos Amazônicos-PLADES/NAEA/UFPA. Especialista em Educação Ambiental pelo Núcleo de Meio Ambiente-NUMA/UFPA. Professora e Técnica da Secretaria de Estado de Educação (SEDUC). Atualmente cedida para a Universidade Federal do Pará/Pró-reitoria de Graduação e Ensino/ Diretoria de Ensino.
} 
Advanced Amazonic Studies (NAEA), at the Federal University of Para (UFPA), titled "Schools-family farms and the agricultural extractive activities in the state of Amapá: practices and meanings ", under the guidance of prof ${ }^{a} r^{a}$. Ligia T. L. Simonian, defended in March 2005. The study aimed to carry out study on the experiences of the Schools-Familys in the state of Amapa, from the perspective of perceiving them as an alternative to education in rural areas with the potential to contribute to rural development in the state. The discussions for the construction proposal of these schools originate in the struggles by farmers, based on an analysis of their reality found that conventional rural schools did not meet their interests and that the pedagogical proposal for EFA could be a solution for education in rural areas. The article intends to present some issues noted during the development of the research in relation to the acquisition of knowledge through orality, guaranteeing the historical, cultural, social and economic rescue in a contexts of a given historical moment.

Keywords: History. Memory. Agricultural Education.

\section{Contextualização do estudo dissertativo}

\subsection{As Escolas-Família Agrícola e Agroextrativistas no estado do Amapá: significados}

Os registros sobre esta temática, educação rural, movimento social rural, políticas públicas para o meio rural ainda são poucos se comparados com as produções destas questões vinculadas à realidade urbana. Contemporaneamente, a organização dos movimentos sociais no meio rural inicia-se na década de 1970 e fortalece-se na década de 1980. Os Sindicatos de Trabalhadores Rurais (STR), movimento dos seringueiros, a organização dos movimentos dos posseiros, do Movimento dos SemTerra (MST), do movimento das quebradeiras de coco, atingidos das barragens, remanescentes de quilombos foram atores importantes nesse momento. Em relação ao quadro educacional, a população rural apresenta uma realidade objeto de crítica. Segundo Censo Escolar de 2002, 50\% das escolas rurais têm apenas uma sala de aula e oferecem exclusivamente o ensino fundamental, de $1^{\mathrm{a}}$ a $4^{\mathrm{a}}$ séries. E a população rural é capaz de elaborar críticas sérias sobre este quadro no sentido de identificar este problema. O que pode ser verificado no depoimento do pai de aluno 
em entrevista, onde afirma que "[...] no meio rural só fazem escolas de $1^{\mathrm{a}}$ a $4^{\mathrm{a}}$ série como se não precisasse ter outras séries". Muito embora tenha tido um aumento, no estado do Amapá, no número de escolas no meio rural com modalidades de $5^{\mathrm{a}}$ a $8^{\mathrm{a}}$ séries, estas ainda não conseguem suprir as necessidades da população. A concepção implícita é de que estas populações necessitariam cursar até a $4^{\mathrm{a}}$ série. Tal posição é decorrente do olhar que se direciona para este grupo social, visto como atrasado, sem cultura, em contraposição à realidade urbana que para Ricci (1999, p. 2) "[...] configura-se como espaço da moralidade, do progresso e do desenvolvimento social".

O estudo de experiências educativas que se pauta de acordo com as especificidades culturais e necessidades econômicas das populações rurais é de grande relevância para a proposição de uma educação que resgate o caráter peculiar da vida rural, haja vista essa realidade educacional ter sido submetida de acordo com a história da educação brasileira às diretrizes e princípios da educação urbana, ou seja, uma educação que, se sabe possuir valores e culturas próprias e valorosas. tem sido submetida à dominação de valores exógenos. Essa evidência deve-se a ausência de uma maior democratização quanto às inovações educacionais que vêm acontecendo no meio rural, como as EFA, que em seu trabalho com a pedagogia da alternância, podem se constituir em alternativa de educação rural diferente das escolas rurais convencionais, por estimularem ações associativistas nas comunidades envolvidas, maior participação das famílias, o fortalecimento de seu capital social, através de práticas de solidariedade e cooperação, e principalmente uma educação significativa que considere a realidade vivenciada pelos alunos relacionando teoria $\mathrm{e}$ prática.

A pedagogia da alternância alia os conhecimentos formais escolares aos conhecimentos da família do agricultor, contribuindo para o fortalecimento do trabalho com a agricultura, pecuária, extrativismo, piscicultura e enriquecimento de suas experiências de vida e trabalho. Este trabalho teve como objetivo central a análise das EFA e EFAEX em sua trajetória histórica e política enquanto iniciativa do movimento social rural local, para a verificação de suas possíveis contribuições para o processo de desenvolvimento do meio rural do estado do Amapá, com vistas à sustentabilidade regional e sua organização por meio de uma Rede das 
Associações das Escolas Famílias Agrícolas e Agroextrativistas do Amapá (RAEFAP), uma entidade civil sem fins lucrativos, de caráter educativo, cultural e social. Esta rede tem como princípios teórico-metodológicos, possíveis contribuições para um novo estilo de desenvolvimento da Amazônia considerando as potencialidades ambientais e suscitando uma consciência crítica loco-regional com relação ao meio ambiente. Para se trabalhar os tópicos acima citados, em especial os que tratam da história do movimento social rural no estado do Amapá, o processo de criação dessas escolas, o seu fazer pedagógico, tivemos que recorrer às entrevistas, à história oral, ouvir o que os atores sociais envolvidos tem a dizer uma vez que é "preciso ouvir o que tantos têm a dizer. Falar sempre, exibindo dúvidas, incertezas e limites. Do conflito e do diálogo dos conhecimentos existentes nas redes formadas é que posso aprender e, talvez, ensinar" (ALVES, 2001).

O eixo teórico da dissertação são as categorias movimentos sociais e pedagogia da alternância, desenvolvimento sustentável e educação para a sustentabilidade e suas revisões a fim de incorporarem o discurso da educação para a sustentabilidade, e sua articulação para o alcance do desenvolvimento rural sustentável proposto pelas EFA. Analisando-se o caráter do papel do Estado e sua perspectiva de desenvolvimento pensado para a Região Amazônica, e sua ingerência no sentido de consolidar as políticas propostas dentro de um Plano Nacional de Desenvolvimento, vinculado a uma visão de desenvolvimento compromissada com a perspectiva de prioridade ao pensamento economicista da busca do crescimento econômico a qualquer custo, o que gerou uma grande perda nas potencialidades dos recursos naturais da região.

As categorias teóricas descritas acima foram delineadas nos capítulos que tratam especificamente da história e construção das EFA no estado do Amapá, vinculando-as dentro de um panorama mais amplo como movimentos sociais e educação no meio rural, a definição e os princípios da pedagogia da alternância nas práticas cotidianas das EFA, a trajetória histórica das EFA no estado do Amapá, as origens das EFA no movimento social rural do Amapá enquanto construção de sonhos coletivos, e o fazer pedagógico das EFA e seus resultados no fortalecimento do agroextrativismo familiar rural das comunidades rurais envolvidas nesta proposta pedagógica. Elaborou-se um quadro teórico, encaixando 
as considerações teóricas produzidas sobre a temática e o conhecimento empírico resgatado das falas e observações realizadas, com o objetivo de indicar as possibilidades de implementação prática da educação para a sustentabilidade a partir da análise das concepções apresentadas pelos atores sociais envolvidos, construindo-se assim uma caracterização da educação desenvolvida por estas escolas e os entraves de sua relação institucional com o poder público, enquanto mecanismo de articulação política a partir de inserção deste movimento social rural.

O estudo de caso foi a opção metodológica utilizada para adentrar nestas realidades, o que para Yin (2001, p. 67-68) é denominado de estudo de casos múltiplos, assumindo questões do tipo "como" e "por que":

[...] onde cada área pode ser o objeto de um estudo de caso individual, e o estudo como um todo teria utilizado um projeto de casos múltiplos. Projetos de casos múltiplos possuem vantagens e desvantagens distintas em comparação aos projetos de caso único. As provas resultantes destes casos são consideradas mais convincentes, e o estudo global visto como sendo mais robusto, e ao mesmo tempo o fundamento lógico para projetos de caso único, não pode ser satisfeito por casos múltiplos.

Este estudo foi realizado em quatro escolas: EFA do Pacui (EFAP), EFA da Perimetral Norte (EFAPEN), EFAEX do Carvão (EFAC) e EFAEX do Maracá (EFAEXMA), todas localizadas em áreas rurais do estado do Amapá. O trabalho de campo obedeceu a um período de dois meses e 15 dias. Neste foi realizado entrevistas com monitores, coordenadores, alunos, pais de alunos, assessoria pedagógica, lideranças sindicais, pessoas mais antigas/idosas nas comunidades onde estão localizadas as escolas, o que oportunizou o conhecimento da história do lugar, que em geral, sua população mais jovem desconhece. Tal evidência gera o que Thompson (1992:25) defende, que "os historiadores orais podem escolher exatamente a quem entrevistar e a respeito de que perguntar. A entrevista propiciará, também, um meio de descobrir escritos e fotografias que, de outro modo, não teriam sido localizados". A produção científica implica em ampliação do conhecimento empírico, do senso comum. Berger (1985, p. 37) afirma

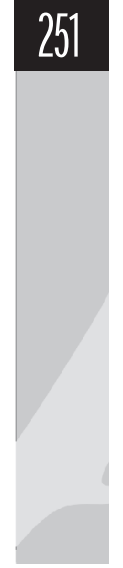


que o "[...] o senso comum contém inumeráveis interpretações précientíficas e quase - científicas sobre a realidade cotidiana, que admite como certas. Se quisermos descrever a realidade do senso comum temos de nos referir a estas interpretações". Desta maneira, analisar as diferentes realidades das EFA do estado do Amapá significa inserir-se nas diferentes realidades apresentadas, ou seja, a EFAP, a EFAPEN, a EFAC, a EFAEXMA. O desafio foi maior considerando as diferentes realidades com suas especificidades e múltiplas faces.

E em se tratando da história de experiências de educação inovadora nesse campo, assim como da história da organização social dessas comunidades rurais ainda, é mais intensificada a lacuna quanto às informações e aos registros históricos. No estado do Amapá são pequenos os registros sobre a história dos municípios e inexistem históricos sobre os distritos onde se localizam as EFA. A EFAP encontra-se localizada no distrito de Pacui, município de Macapá. No município de Mazagão estão duas EFA, a EFAC, no distrito de Carvão, e a EFAEXMA, na vila do Maracá. A EFAPEN localiza-se na Rodovia BR 210, Perimetral Norte, no município de Pedra Branca do Amapari. A dificuldade para coletar dados sobre estes foi grande devido à dificuldade já mencionada de acesso às informações. E neste momento tivemos que recorrer às memórias sociais dos moradores do local, ou seja, as pessoas mais idosas que detém o conhecimento do processo de construção da comunidade, que acompanharam seu crescimento e seu desenvolvimento resgatando sua cultura, história, religiosidade, formas produtivas etc.

\section{A história oral como mecanismo de reavivar as origens da localidade}

Pensar o passado não deve ser entendido como exercício de saudosismo, mera curiosidade ou preocupação erudita. $\mathrm{O}$ passado não deve ser encarado como algo morto ou arquivado: nele estão as raízes do presente (ARANHA, 1989).

A utilização da história oral como recurso para as investigações de historiadores ou outros estudiosos não se constitui em consenso do ponto de vista metodológico. No entanto, de acordo com Santos (2000), desde as "décadas iniciais do século XX, diversos sociólogos e antropólogos norteamericanos fizeram uso de relatos orais em suas investigações. Mesmo no Brasil, a utilização de relatos orais em pesquisas acadêmicas remonta 
aos anos de 1950, também nas ciências sociais. Contudo, foi apenas no contexto da "Nova História" que as fontes orais fizeram sua reentrada no campo desta disciplina, embora ainda continuem a enfrentar resistências da parte de alguns historiadores". (SANTOS, 2000:2).

Simonian (2001, p. 107-148) utiliza-se da história oral enquanto instrumento metodológico, para dissertar sobre a participação das mulheres nos trabalhos dos castanhais do sul do Amapá, resgata não somente as relações de trabalho desse processo produtivo como, ainda, a cultura dessa população. E dentro dessa linha de raciocínio Thompson (Id., p. 19) afirma que:

a história oral possibilita novas versões da história ao dar voz a múltiplos e diferentes narradores. Este tipo de projeto propicia fazer da história uma atividade mais democrática, a cargo das próprias comunidades, já que permite a partir das próprias palavras daqueles que vivenciaram e participaram de um determinado período, mediante suas referências e também seu imaginário. O método da história oral possibilita o registro de reminiscência das memórias individuais, enfim a reinterpretação do passado".

Esta afirmação é compatível com os depoimentos tomados pelas pessoas possuidoras de uma significativa memória social, como o de seu Sabá Jucá (68 anos) morador da Vila do Maracá:

O meu pai veio com 18 anos do Ceará, viveu 105 anos, teve 6 meses com o bando do Lampião, depois cansou e também porque minha mãe pediu pra ele sair e ai ele veio pra o Amapá, aqui ele era jagunço do Zé Júlioº , ele tinha a medalha do padre Cícero; a gente gastava 12 dias a remo para ir pra Santana pra

\footnotetext{
${ }^{2}$ José Júlio, considerado o maior latifundiário do mundo, foi comerciante, seringalista e Intendente do município de Almerim. Iniciou o processo de ocupação econômica da região através de expropriação e concentração de terras em suas mãos, submetendo a população residente à forma do trabalho compulsório, utilizando-se do aviamento e da violência. Suas terras no estado do Pará, municípios de Almerim, Porto de Moz, e território federal do Amapá poderiam chegar a 3 milhões de hectares.
} 
vender a farinha que a gente fazia; hoje tudo é fácil, tudo esta melhor, antes era tudo com lamparina, hoje não se sabe dormir sem energia. o primeiro morador foi um senhor por nome Joaquim Vicente, veio do Ceará, morava no lugar de nome Careca, depois veio o genro dele,a primeira casa daqui é onde é hoje a casa do seu Pedro. Maracá tinha muita fartura, jacaré se podia sair, queixada, porco do mato tinha demais em grande numeridade, meu pai contava que era a porteira do curral da cabanagem, o pessoal que morava lá tinha orelha grande por isso se chamava cabano; antes falava no mapa que tava no campo geral, tinha riqueza no rio, que era tudo dos cabanos... depois ficou um bacabal; tem muita cachoeira nas áreas altas: Pancada é a primeira cachoeira, Cuamba, Piranha, Paca, Angelim, Tucumã, Anariai, Caranã, Varador, é uma das mais grandes da região. Tem dois anos que caboclo do Maracá ganha dinheiro, quando a estrada já varou no Carana, falta só ser beneficiada para o Carana fica mais fácil, e aumento pra quem trabalha com a castanha, o caminho ficar mais fácil com o atalho da estrada; a estrada pronta pra carro só tem 14 anos; antes era tudo mata pesada, desde matapinguari tinha aqui, bicho do mato que come gente, existia aqui; a igreja católica tem 13 anos que a comunidade aqui construiu, depois é que chegou o padre; a festa que tem é a do São Tomé, padroeiro da vila, os primeiros que festejaram já faleceram, mas foi passando de família pra família e por isso até hoje existe, o meu pai quando chegou aqui já tinha essa festa, dizem que foram os antigos que trouxeram; a vila tem 14 anos, antes era apenas alguns moradores; as primeiras casas foram feitas com mutirão pelo prefeito de Mazagão, por nome pureza; a minha mãe fazia esteira de táboa para colocar embaixo da rede. a praga era a muriçoca, não se sabe se é o óleo, gasolina, que se tá incluindo na água que muriçoca não tem mais hoje, outros bichos também como a cobra. Trabalhei com a borracha, a quinzena que eu fazia era de 15 dias no trabalho com a borracha; estou esperando a aposentadoria do soldado da borracha. Coloquei um sapato no pé quando tinha 
15 anos, que não conseguia nem andar, hoje é tudo fácil e o pessoal ainda reclama; trabalhava com as seringueiras, primeiro a borracha, depois o leite, o látex, cortava no mato e colocava o leite em um tanque grande, retirava o leite fazendo as marcas na árrvore, tinha a bandeira brasileira a espinha do peixe, que fazia na seringueira, com um balde de cuia aparava o leite. A borracha quem comprava era Zé valente para vender para o exterior. Tirava fora e ia vender no comércio, comprar as necessidades, a alimentação, roupa, mosquiteiro; a seringa era tirada no verão; no inverno era a castanheira, pra cima ainda tem muita, trabalhei com maçaranduba pra tirar leite, cozinhava pra fazer o bolão (borracha) e a solva, colocava em uma forma grande. Hoje é o que tá na frente é a castanha que nunca perdeu. Peixe dá, mas não como antes; tracajá dava muito ovo nessa área; a vila era cheia de ninho com ovo; é muito difícil jacaré hoje, antes cachorro não latia na beira do rio, acabou porque entrou a compra da pele, aonde sabia que tinha jacaré o pessoal ia e matava pra tirar o couro, mas não acabou, apenas afugentou. Há de ter um lugar pra separar eles para ninguém ir lá; o que Deus criou não acaba tem lugar que existe par ninguém passar lá para guardar os bichos e a mata. Ainda tem muita castanha pra dentro, não acaba assim não; onde tem fartura o pessoal não liga (Seu Sabá Jucá).

O depoimento do senhor Sabá Jucá, considerado uma das pessoas mais antigas na Vila do Maracá, permitiu a descrição da realidade sob o olhar de alguém que, apesar do ponto de vista de uma subjetividade fantasiosa e limitada, permite o conhecimento da realidade de um passado nos aspectos econômicos: a economia da borracha, formas de produção, política de exportação; ambientais: perda da qualidade ambiental exemplificado na perda das seringueiras, castanheiras, animais, poluição dos rios; religiosidade; modificações trazidas com a modernidade, a energia, a abertura de estradas que ocasionou a melhoria no escoamento da produção. Aparentemente sua visão

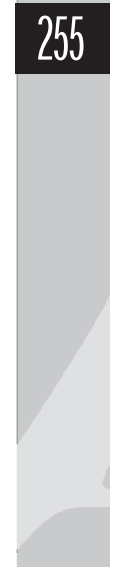


sobre o assunto é parcial e limitada àquilo que seus olhos viram e que seus ouvidos escutaram. Tratase, enfim, de sua história de vida; é ele quem define quem e quais acontecimentos devem dela participar. Entretanto, a narrativa daquilo que foi vivenciado (real ou imaginariamente) $[\ldots]$ nos permite descortinar, além de eventos e personagens reais, o imaginário e as representações da sociedade [...] sobre o seu próprio passado. (SANTOS, 2000, p. 2).

As declarações apresentam a diversidade de riquezas oriundas das experiências existenciais vivenciadas por este ator social que consegue resgatar uma enormidade de informações advindas desta vivência. $\mathrm{O}$ que se percebe é que mesmo quando não tem o controle da situação, conhecimento sobre o assunto, como no caso do movimento da Cabanagem $^{3}$ ele constrói formulações de acordo com o seu imaginário social, imaginário este que se relaciona à visão que é repassada pela historiografia oficial sobre o movimento da Cabanagem como um fato histórico com caráter subversivo, de transgressão às leis e às normas impostas pelo poder estatal, daí a visão de "bicho papão" dado aos cabanos por seu Juca Sabá. Hall (1992, p. 157-160) enfatiza que "hoje em dia somos todos um pouco menos ingênuos, me parece, e reconhecemos que a história oral está longe de ser uma história espontânea, não é a experiência vivida em estado puro, [...] os relatos produzidos pela história oral devem estar sujeitos ao mesmo trabalho crítico das outras fontes que os historiadores costumam consultar".

A importância da utilização da história oral enquanto suporte metodológico em um trabalho desse porte é de grande contribuição no sentido de propiciar o acesso à história a quem não a tem, e ainda garante a construção de uma história que só existe na lembrança de algumas pessoas

\footnotetext{
${ }^{3}$ Cabanagem, para Júlio José Chiavenato, foi o único movimento popular no Brasil em que o povo toma o poder. Não por acaso é uma guerra "esquecida". Quando é lembrada é para dizer que os cabanos eram uma ralé de malfeitores e bandidos que tomaram de assalto Belém do Pará, em 1835, promovendo a desordem e saqueando as lojas ou incendiando propriedades. Isto porque, no seu grande momento, negros, índios, mulatos, cafuzos, tapuios e brancos pobres, matam governadores, expulsam o poder que os oprime e subvertem de fato a situação política no Pará.
} 
que, em geral, encontram-se idosas, podendo perder as lembranças. No entanto, apesar dos questionamentos quanto à validade da credibilidade das fontes orais, ela apresenta-se de extrema relevância para a reconstrução de histórias sob outras versões e perspectivas, permitindo a ampliação e a flexibilidade do conhecimento de uma realidade que até então era tida como absoluta.

Thompson afirma que (1992, p. 18)

\begin{abstract}
para alguns historiadores tradicionais os depoimentos orais sã̃o tidos como fontes subjetivas por nutriremse de memória individual, que as vezes pode ser falível e fantasiosa. No entanto, a subjetividade é um dado real em todas as fontes históricas, sejam elas orais, escritas ou visuais. O que interessa em história oral é saber por que o entrevistado foi seletivo, ou omisso, pois essa seletividade com certeza tem o seu significado.
\end{abstract}

Mas, em se tratando do resgate histórico de uma dada realidade, apesar da forte presença da subjetividade, se pode inferir análises significativas acerca desta mesma realidade, e esse é o papel do cientista social, do pesquisador que trabalhe dentro de uma perspectiva crítica, desvendar cada depoimento apresentado à luz de sua matriz epistemológica, possibilitando que as histórias até então encobertas possam ser desveladas e estudadas. Para Montenegro (1992, p. 9),

"o espaço onde se constrói uma cidade nos convida para o reconhecimento de um espectro infinito de determinações/relações. É nesse plano intrincado que homens, mulheres, crianças, velhos e velhas estabelecem, projetam, realizam suas vidas. O que fazem, o que inventam o que transforma está além de qualquer possibilidade positiva de determinação".

É com esta compreensão que se construiu este artigo.

Dona Lucimar (66 anos) e seu Joaquim Ramos Cordeiro (64 anos), irmãos e filhos de um dos primeiros moradores do distrito de São Joaquim do Pacui, e dona Conceição (64 anos), filha também de um dos primeiros moradores da localidade, assim como seu Ciro Ramos, agente distrital, também em seus depoimentos descrevem as mudanças 
ocorridas principalmente quanto às questões ambientais, o que resultou na diminuição significativa da pesca, caça. Outra questão apontada no depoimento de seu Ciro é quanto à alteração na estrutura administrativa do estado do Amapá ${ }^{4}$ gerando uma determinada paralisia no trabalho com a agricultura devido ao vinculo e ocupação com a esfera pública, na sua maioria a população passou a ser funcionária pública, demonstrando, assim, alguns pontos que contribuíram para a reconstrução da história da vila de São Joaquim do Pacui.

A atividade econômica era a roça, pesca para alimentação; não é como hoje que planta tudo, naquele tempo era só farinha. A gente fazia a farinha aqui e vendia no Bailique, mais de 1 (um) dia e uma noite de viagem no remo, pra Macapá era 8 dias de viagem; a farinha para Macapá ia de barca a vela. A primeira rua foi onde a nossa família mora. A primeira escola do governo foi criada em 1950. As primeiras professoras eram do Igarapé do Lago. Os meus pais pagavam uma professora particular para dar aula para os filhos, o meu pai trazia pessoas que tinha estudo pra alfabetizar. Quando eu fui pra escola pública já tava alfabetizada. A primeira escola particular foi do Anastácio, a minha primeira professora da escola do governo foi de nome Safira de Carvalho Costa. O meu pai fez dois campo de aviação a braço. No tempo de Coaraci Nunes, Pauxis Nunes, que eles chegavam de avião no local. Não tinha gente mais interessado do que meu pai por esse lugar. Tinha um padre, Antônio Arcanjo, que vinha e dava missa em qualquer casa. $\mathrm{O}$ sr. Alessandro criou as comunidades, junto com a esposa que iam de barco pequeno atrás das crianças. No sítio, nome Garimpo, tinha o lugar do giral, quando a roça foi queimada tinha os restos de cerâmica. Em Santa Luzia do Pacui tem cemitério indígena, tem alunos que está fazendo uma pesquisa. Primeira ocupação indígena, os primeiros posseiros ficaram na boca de Cipriano Vitalino. A SUCAM faz

\footnotetext{
${ }^{4}$ O Território Federal do Amapá transformou-se em Estado da federação em 1988 ocorrendo a promoção da reestruturação política e administrativa nacional.

${ }^{5}$ Políticos importantes no cenário político local, regional e nacional na década de 1930 e 1940.
} 
muito tempo que estão por aqui, 5 ou 6 anos está o escritório da SUCAM. A estrada foi aberta no tempo do Cleyton, que estava substituindo outro prefeito e foi o primeiro a varar aqui; trabalhava muito, fez o pedaço do Corre Água, iam de pé pra o Corre Água, que fica a mais ou menos $7 \mathrm{~km}$. Mulheres faziam as mesmas coisa dos homens, não era como hoje que é separado. Ficam só esperando que o marido bote tudo, eu não, eu quero ter o meu dinheiro. As frutas do mato: bacaba, inajá, tucumã, hoje tem pouco açaí. O meu marido tá pagando gente pra cuidar da roça porque não tem gente da família pra cuidar (Dona Lucimar).

Este depoimento indica as dificuldades de locomoção devido à distância da capital destacando a farinha enquanto a monocultura predominante. A organização geográfica da vila, atualmente a rua indicada por D. Lucimar, é considerada rua principal da localidade. O surgimento da escola, da igreja e o papel de liderança de seu pai no sentido de buscar a melhoria do local para demonstrar para as autoridades. Indica ainda as origens indígenas enquanto os primeiros moradores demonstrados pela presença dos sítios arqueológicos na região.

Antes a situação era a gente pegava o peixe quando queria, hoje a gente compra tucunaré a $\mathrm{R} \$ 5,00$. O igarapé ficava alto, enchia na cheia, ficava na altura de um pau alto, hoje não fica abaixo nem da metade do pau, porque não soubemos preservar o igarapé. Hoje a gente toma cuidado pra não secar. O desmatamento acaba com tudo, falei pra uma técnica da SEMA (Secretaria de Estado de Meio Ambiente) fazer a limpeza na beira do igarapé, mas nunca mais apareceu aqui. Antes tudo era dividido pesca, caça, hoje tem que comprar. Antes a gente tinha o mutirão ou convidado ${ }^{6}$, cada um tinha uma função. Matava um capado e chamava homens, mulheres, rapazes era uma festa, hoje é só você ninguém aparece pra ajudar. É chamado Pacui porque antes a gente

\footnotetext{
${ }^{6}$ Sistema de ajuda recíproca que implica solidariedade entre as partes envolvidas objetivando a realização de um empreendimento: derrubada de mata, construção de casa, procura de caça.
} 
jogava uma muncheada ${ }^{7}$ de farinha na cuia, pegava os pacui e assava sobre a folha na brasa. Pacui quer dizer pacu $^{8}$ pequeno. No período de alta produção da farinha, a comercialização acontecia em Itaubal, duas cargas por semana, era o auge da farinha. (Seu Joaquim Cordeiro)

A caça não existe mais, estamos aproveitando o campo porque a floresta nativa não existe mais. Aqui já teve a maior quantidade de produção de farinha, quando passou a ser estado as pessoas passaram a ser funcionário público e deixaram de trabalhar na terra pra receber um salário. Hoje a maioria compra farinha. A pesca só pra alimentação e apenas no verão. Aqui já teve a maior quantidade de produção de farinha, quando passou a ser estado as pessoas passaram a ser funcionário público e deixaram de trabalhar na terra pra receber um salário. Hoje a maioria compra farinha. A pesca só pra alimentação e apenas no verão. Desemprego é a maioria, as pessoas se iludem com o emprego público, mas eu costumo dizer que é a terra é tudo. (Seu Ciro Ramos)

Tinha muito peixe (tucunaré, traíra), a gente pescava muito. Pra gente puxar traíra era rapidinho! Punhava o cacuri e pegava acará, mapurá, todo o tipo de peixe se pegava de cacuri. Hoje em dia, eu mesma não pesquei mais porque não dou conta. Olhe, sempre aqui, acolá, o pessoal pesca. Não tem nem a metade, cê sabe, né? Povoou. Aí, um bate com uma malhadeira, uma tarrafa ${ }^{9}$, o peixe foi acabando. O rio pequeno, foi ficando mais difícil. Já não tem como teve. De primeiro, logo quando me casei, a gente ia trabalhar, aí, quando voltava, não tinha comida. Aí "umbora pescar". Aí, rapidinho era uma cambada. Pois é, pra vista que tinha, hoje em dia não tem mais, porque povoou. [...] Olhe, eu não tô bem lembrada quem começou esta estrada, mas a gente ia por terra.

\footnotetext{
${ }^{7}$ Mão cheia.

${ }^{8}$ Peixe de água doce próprio dos rios da Amazônia, nome de origem indígena.

${ }^{9}$ Redes de pesca utilizadas para pescar na região. Tarrafa é uma rede de pesca, circular com chumbo nas bordas e ao centro uma corda, que permite retirá-la fechada da água.
} 
Aí, logo que começou a gente pegava o carro lá na localidade no Piriri e no Bacaba. Uma vez, minha filha veio, a que morava em Macapá, quando eu fui deixar ela, inchou o mocotó, que a gente levava farinha na costa até o Curicaca. Tudo a gente levava carregado e apanhava o carro no Curicaca. Depois, passou pra ai pro Bacaba. A gente ia daqui sempre carregando o trosso e panhava o carro no Bacaba, do lado de lá da Ponta Grossa. A gente passava um bucado de sacrifício (Dona Conceição).

Os depoimentos indicam as alterações ocorridas, em especial com o povoamento da região, consequência da transformação do Território Federal do Amapá em estado da federação, no ano de 1989, fazendo com que a maioria da população, transformando-se em funcionário público, abandonasse a agricultura, e apesar da ênfase de Seu Ciro na importância da terra, ele também, de acordo com a esposa, afastou-se desta preocupandose mais com a função de Agente Distrital. Outro aspecto de mudança do local deve-se a valorização do seu potencial turístico, que assim como pode trazer benefícios, no sentido do crescimento da economia local, pode gerar problemas sérios no que se refere às alterações no modo de vida da população, principalmente da juventude, que de acordo com os depoimentos se encontram desocupados e sem perspectiva de um futuro promissor.

No distrito do Carvão, localizado no município de Mazagão, a origem da história da formação da vila do Mazagão, remonta ao imperialismo ibérico na porção setentrional do continente africano entre os séculos XVI e XVIII. ${ }^{10} \mathrm{E}$ ainda nos dias de hoje a população do

\footnotetext{
${ }^{10} \mathrm{O}$ grande obstáculo à dominação lusa nessa região foi a resistência dos mouros contra a expansão cultural europeia materializada principalmente através da fé cristã. Em virtude dos frequentes conflitos étnico-culturais, a colonização nessa parte da África se tornou uma empreitada de elevado custo à Coroa portuguesa. Com a falência da Mazagão Africana,colônia portuguesa, hoje ocupada pelo Marrocos, criou-se a vila de Mazagão Amazônica, na margem esquerda do rio Mutuacá, onde logo foram assentados 163 famílias, sendo os primeiros habitantes 114 brancos e 103 escravos, transformandose nos primeiros agricultores desta região. Inicialmente foram hospedados em Belém, onde permaneceram até junho de 1771. Por volta de 1915, o governador do Pará resolve incorporar esta vila ao município de Macapá, devido à situação sócio-econômica e política.
} 
município de Mazagão se mantém com uma de suas atrações turísticas e culturais, a festa de São Tiago, que é a reprodução das lutas entre mouros e cristãos. E a própria história de luta para a conquista de seus direitos como educação, saúde, abertura de estradas foram construídas com o esforço de sua população. O depoimento de seu Tomé conta sobre esse processo.

A história do Carvão é meio complicada [...] Aqui era quilombo, era refúgio dos escravos, naquela época quando os portugueses vieram, trouxeram muitos escravos, você sabe que escravo era obrigado a trabalhar e muitos fugiam. Aqui nós temos três regiões que surgiu por quilombola que é o Carvão, o Maracá e o (?), O carvão foi descoberto por um caçador, naquele tempo os patrões tinham aquela pessoa que caçava pra eles comerem, aí ele foi caçar e se perdeu e veio varar aqui no Carvão. Uma pessoa de 104 anos que contou toda essa história, então quando ele chegou e disse que eles teriam um lugar pra ficar refugiado por muitos anos e isso eles fizeram. Naquela época, aqui era deserto, não tinha habitante, não tinha nada, eles sofreram bastante, tiveram que começar a vida, mas depois que houve as libertações tomaram fôlego e começaram, aí começou a chegar as famílias. No Carvão chegou a morar 26 famílias quando se transformou em território. O Camilo da Luz foi intendente e isso deu revolta porque naquela época os brancos não queriam que os negros subissem e como ele era negro, era da família Luz, ele sofreu uma repressão muito grande a ponto dele ter de renunciar ao mandato antes de terminar porque a pressão política era muito grande. Os brancos que assumiram da família Flexa fez uma pressão muito alta e ele teve que renunciar antes da hora o cargo. [...] Quando passou a território o pessoal começou a ir embora daqui, chegou um momento que isso aqui ficou deserto, sem ninguém que morava aqui. Algumas pessoas moravam lá na vila, e só tinha roça aqui. $\mathrm{O}$ patrão alugava a propriedade e você teria que vender direto para o patrão e isso foi por muito tempo. Em 1969 quando a igreja retoma todo o trabalho de base com o padre. Aí ele começou a dizer 
"por que vocês não criam uma comunidade" e logo em 69 nós abrimos esse ramal aqui no machado, na enxada, de lá da beira da estrada até na beira daquele lago, era muito chão. Nós fizemos $3 \mathrm{~km}$ de distância. Quando a gente abre a estrada, aí começa a discutir e o padre disse: "vamos fazer uma capela", onde hoje se reúne os alcoólicos anônimos. Construímos escola pressionando o prefeito, o posto de saúde, melhoria na estrada.[...] A vantagem do Carvão é que ela é um comunidade que cresce, mas o povo não tem um vínculo empregatício, o povo continua trabalhando na agricultura, plantando, criando as suas pequenas criações. Então por isso a comunidade do Carvão 'tá' crescendo organizadamente porque o povo não 'tá' olhando só pro emprego, os empregados que nós temos no nosso município, em nossa comunidade é professor, enfermeiro, a parte grossa, ninguém é empregado.

A reflexão acima indica que

Estaremos percorrendo representação de caráter universal, onde o ser próprio, porém, encontra-se em um movimento e em relação permanente com determinações específicas; onde a própria razão de ser se define como algo particular e próprio de aspectos específicos da formação social sem, no entanto, perder seu elo, sua relação com planos gerais/universais (MONTENEGRO, 1992, p. 10).

Diferente da população da vila do Pacui, a população de Carvão, na sua maioria, ainda vive da agricultura, demonstrando um maior apego a sua cultura e a valorização da sua origem étnica. Percebe-se certa organização e participação de jovens nas atividades realizadas pela comunidade religiosa, cuja religião predominante também é a católica. O destaque apresentado por Seu Tomé das conquistas, conseguido pela comunidade, deve-se à organização e formação política a qual teve uma forte contribuição da igreja católica, que ajudou na mobilização da comunidade uma vez que esta já possuía esta força em potencial, até pela sua trajetória histórica. 


\section{Considerações finais}

Para finalizar há que se destacar a utilização da história oral como a constituição da memória viva, a história viva, feita por homens e mulheres comuns, do nosso dia-a-dia, que são os verdadeiros construtores da história, ou seja, a construção de uma escola, de um posto de saúde, de uma pista de aviação, de uma estrada começa sempre enquanto iniciativa de um grupo social organizado. $\mathrm{O}$ Estado apenas intervém no sentido de implementação de uma demanda que a população em geral exige sob pressão. E a historiografia oficial repassa que a iniciativa é de quem possui a hegemonia, seja econômica, política, cultural, etc. E de acordo com Thompson (id. p. 28), com a história oral "amplia-se e se enriquece o próprio campo de ação da produção histórica; e ao mesmo tempo sua história social se modifica. Para ser claro, a história se torna mais democrática. A crônica dos reis introduziu suas preocupações a experiência de vida das pessoas comuns".

Infelizmente ainda há uma lacuna muito grande e significativa quanto à valorização do conhecimento oriundo dos sujeitos que viveram e fizeram a história de uma dada localidade ou região. Esta história tem ficado sem ser contada porque não há registros seguros e concretos sobre elas, no entanto ela está viva e poderá nos dizer muito sobre as diferentes e diversas ambiências apresentadas e estabelecidas. O sujeito responsável em processar e repassar as informações é incitado a reviver fatos, acontecimentos, a rememorar, a lembrar acontecimentos e pessoas com as quais conviveu em outros espaços e tempos. E a referência que possui para retornar é o momento e tempo presente, "ainda que nem sempre expresso em palavras, que serve de ponto de partida para a rememoração. Voltar no tempo é um exercício que necessita de um constante ir e voltar, pois cada lembrança ancora-se a um momento do presente". Nesse sentido, a constatação de que o tempo presente é parâmetro para as análises futuras partindo do passado, é essencial para que possamos compreender a importância de olhares de sujeitos como os relatados neste artigo que ajuda-nos a ressignificar a história a luz da história significativa e viva. 


\section{REFERÊNCIAS}

ALVES, N. Decifrando o pergaminho: o cotidiano das escolas nas lógicas das redes cotidianas. In: Pesquisa no/do cotidiano das escolas: sobre redes de saberes. Rio de Janeiro: DP\&A, 2001. p. 13-38.

ARANHA, M. L. A. História da educação. São Paulo: Moderna, 1989. 288 p.

HALL, M. História oral: os riscos da inocência. O direito à memória. São Paulo: Secretaria Municipal de Cultura, 1992, p. 157-160.

MONTENEGRO, A. T. História Oral e Memória: a cultura popular revisitada. Rio de Janeiro: Editora Contexto, 1992.

O' DONNEL, G. Sobre o estado, a democratização e alguns problemas conceituais: uma visão latino-americana com uma rápida olhada em alguns países pós-comunistas. Tradução Otacílio Nunes. Novos Estudos/ CEBRAP, n. 36, São Paulo, 1993. p. 123-145.

RICCI, R. Esboços de uma nova concepção de educação do meio rural brasileiro. Disponível em: < http://www.serrano.neves.nom.br/ dowloads/educrural.pdf $>$. Acesso em: 24/10/2003.

SANTOS, A. C. A. Fontes Orais: testemunhos, trajetórias de vida e história. Cópia cedida, 2000.

SIMONIAN, L. T. L. Mulheres da Amazônia brasileira: entre o trabalho e a cultura. Belém: UFPA/NAEA, 2001.

THOMPSON, P. A voz do passado: história oral. Tradução Lólio Lourenço de Oliveira. Rio de Janeiro: Paz e Terra, 1992.

YIN, R. K. Estudo de caso: planejamento e métodos. $2^{\text {a }}$ Ed. Tradução Daniel Grassi. Porto Alegre: Bookman, 2001. 